\title{
Factors influencing e-collaboration for knowledge development and innovation
}

\begin{tabular}{|c|c|}
\hline \multicolumn{2}{|c|}{$\begin{array}{l}\text { Authors: } \\
\text { Tendani J. Lavhengwa }{ }^{1} \\
\text { Jacobus S. van der Walt }{ }^{1} \\
\text { Eve M. Lavhengwa }\end{array}$} \\
\hline \multicolumn{2}{|c|}{$\begin{array}{l}\text { Affiliations: } \\
\text { 1D Department of Informatics, } \\
\text { Tshwane University of } \\
\text { Technology, South Africa }\end{array}$} \\
\hline \multicolumn{2}{|c|}{$\begin{array}{l}{ }^{2} \text { Audit Services, Department } \\
\text { of Minerals Resources, } \\
\text { South Africa }\end{array}$} \\
\hline \multicolumn{2}{|c|}{$\begin{array}{l}\text { Correspondence to: } \\
\text { Tendani Lavhengwa }\end{array}$} \\
\hline \multicolumn{2}{|c|}{$\begin{array}{l}\text { Email: } \\
\text { usapfa@gmail.com }\end{array}$} \\
\hline \multicolumn{2}{|c|}{$\begin{array}{l}\text { Postal address: } \\
\text { PO BOX 11271, Vorna Valley, } \\
\text { 1686, South Africa }\end{array}$} \\
\hline \multicolumn{2}{|c|}{$\begin{array}{l}\text { Dates: } \\
\text { Received: } 16 \text { July } 2013 \\
\text { Accepted: } 19 \text { June } 2014 \\
\text { Published: } 17 \text { Nov. } 2014\end{array}$} \\
\hline \multicolumn{2}{|c|}{$\begin{array}{l}\text { How to cite this article: } \\
\text { Lavhengwa, T.J., Van der } \\
\text { Walt, J.S. \& Lavhengwa, } \\
\text { E.M., 2014, 'Factors } \\
\text { influencing e-collaboration } \\
\text { for knowledge development } \\
\text { and innovation', SA Journal } \\
\text { of Information Management } \\
\text { 16(1), Art. \#588, } 8 \text { pages. } \\
\text { http://dx.doi.org/10.4102/ } \\
\text { sajim.v16i1.588 }\end{array}$} \\
\hline \multicolumn{2}{|c|}{$\begin{array}{l}\text { Copyright: } \\
\text { (C) 2014. The Authors. } \\
\text { Licensee: AOSIS } \\
\text { OpenJournals. This work } \\
\text { is licensed under the } \\
\text { Creative Commons } \\
\text { Attribution License. }\end{array}$} \\
\hline \multicolumn{2}{|c|}{ Read online: } \\
\hline 口ididn & $\begin{array}{l}\text { Scan this QR } \\
\text { code with your } \\
\text { smart phone or } \\
\text { mobile device } \\
\text { to read online. }\end{array}$ \\
\hline
\end{tabular}

Background: Knowledge development and innovation are at the heart of the progress of academic and research institutions (ARIs) through individual and coordinated research projects. Collaboration initiatives remain a challenge for many researchers for a myriad of reasons which are further intensified by the many technology options that are available both freely and at varying prices. Although multiple theories were considered, the focus on electronic communication supported by the interest in how innovation is diffused and the richness of media motivated the focus on diffusion of innovations (DOI) and media richness theory (MRT).

Objectives: The objective was to develop a multi-dimensional matrix of e-collaboration factors for research institutions. This study investigated collaboration by ARIs while focusing on the supporting and enabling technologies.

Method: The grounded theory method (GTM) was adopted. E-collaboration literature was reviewed followed by data collection using observations, interviews and a blog. DOI and MRT were considered as theories that assist in the implementation of collaboration. A blog was developed as an e-collaboration platform to examine the emergent ideas and to collect data. Data was analysed through the coding method which led to the development of the multi-dimensional e-collaboration factors matrix.

Results: The findings reveal that e-collaboration has multiple factors that must be considered. Collaboration by participants was improved through knowledge development and innovation.

Conclusion: The multi-dimensional matrix of e-collaboration factors presented collaborators with a checklist that will enhance and improve their work. ARIs continue to collaborate at multiple levels depending on their needs and objectives.

\section{Introduction}

Collaboration, the development of knowledge and the improvement thereof for the sake of innovation are important for the research community. Because knowledge development is at the centre of research, academic and research institutions (ARIs) need to remain up to date with the changing electronic environment and requirements. Collaboration can entail one individual or one business, or it could entail multiple academics, institutions, nations or multinationals.

Soliman, Brown and Simoff (2005:372) assert that having a clearer understanding of what collaboration entails can help in with decision-making regarding future technology. The understanding of Soliman et al. (2005) of collaboration needs to be examined and relevant technologies must be identified for present and future use. This understanding will be improved by introducing a multi-dimensional matrix of e-collaboration factors.

Bettoni et al. (2011) observed that participative work is assumed to form part of academic activities. At times, this desire and need to work together is not natural; effort must be made and initiatives must be taken to make it possible. Anyangwe (2012) explain that highereducation institutions and further-education colleges must be prepared to share expertise. This statement is important since it joins ARIs to collaboration. When investigating the value of knowledge workers, Steyn and du Toit (2009:12) asserted that they were encouraged by participants' willingness to share their private knowledge stock and the willingness to using conversations as an approach to obtain the required knowledge. The motivation to focus on the use of electronic communication and blogs came from an investigation conducted by De Jager, Buitendag and Van der Walt (2012). De Jager et al.'s (2012) investigation was supported by the importance of discovering innovative collaborative knowledge. The need to share is thereby essential for various ARIs. There is also an inherent need to investigate supporting technology and derive improved levels of understanding. 
De Jager et al. (2012) state that collaborative knowledge activities are necessary to generate vast quantities of knowledge within multiple domains. E-collaboration is considered as a contributor to knowledge development and innovation where similar challenges exist. This is more prevalent amongst ARIs where one of their core objectives is to conduct research. Understanding the factors that enable e-collaboration can assist in this challenge. The proposed matrix will also bridge the gap on the effective use of e-collaboration.

This article starts by discussing the literature related to driving forces, technology, e-collaboration concepts, knowledge development and ARIs. This is followed by examining the diffusion of innovation (DOI), media richness theory (MRT) and grounded theory method (GTM) as a grounding lens for analysis and discussion. The methodology adopted is GTM. The final outcome is to develop a multi-dimensional matrix of e-collaboration factors for research institutions.

\section{The importance of driving forces and factors}

Forces and factors are used interchangeably in this article. Driving forces or forces working towards achieving an objective are important. The focus is on driving forces for e-collaboration. The work of a number of authors work was reviewed to establish the driving forces as explained in the section below.

Caldwell (2009) listed five commonly used driving forces as follows: science and technology, economics, demographics, political and social. In support of driving forces, Bechina and Ndlela (2009) listed six factors that contribute to the effectiveness of knowledge management systems (KMS). These are leadership, training, clear business strategy, aligning business goal with technology, collaboration and adaptive culture.

Thomas (2013) asserts that collaboration works best for problems that have the following three characteristics measured as forces: There is no obvious solution, the problems lack structure, and the problems require collective volition.

These characteristics are significant since they also act as driving forces for individuals or groups to collaborate. It is also notable that the driving forces provide areas for further analysis.

Collaboration is, furthermore, listed as a driving force for KMS. The Canadian Health Services Research Foundation
(CHSRF) (2003a:1) explains that knowledge brokering is a process of bringing people together and building relationships to make knowledge transfer more effective.

This linking of people can feature researchers, decision makers, practitioners and policy makers. The ability to bring people together and facilitate their interaction is listed as one of the basic skills required by a knowledge broker (CHSRF 2003a:1). The CHSRF (2003b:6) further asserts that there can be no standard definition of knowledge brokering since the job differs from context to context and is seen as an unfolding journey. The need to manage knowledge is central to improving the collaboration, hence the introduction of knowledge brokers who bring together knowledge participants. Technology is another primary driving force which connects collaborators from widely differing geographical areas and which presents multiple opportunities to collaborate.

\section{Technology in the world today}

Tools and technology have become central in facilitating interaction and communication. Tools and technology are used as interchangeable concepts. The days of seeing technology as a 'nice to have' have long passed. We need to acknowledge that technology has become pervasive. It is therefore essential for organisations and ARIs to be able to evaluate technology. Table 1 below shows a list of technological tools that can be used for collaboration, grouped by authors.

It is notable from Table 1 below that there is technology that is commonly used for collaboration. Knowing these can make it easier to work together with other participants to improve collaboration on projects.

In a detailed review, Sahin (2006) confirms the relationship between computer knowledge and the adoption of innovation. This relationship is why it is important to select the best technology for collaboration. It is also noted that the present level of computer knowledge as well as elements for e-collaboration require further investigation.

\section{E-collaboration and key elements}

Today's communication features e-collaboration as an integral component since work is mostly shared over electronic media, more specifically the Internet. With this in mind, it is important to develop an understanding of the origin and key elements of e-collaboration. Kock (2005) describe e-collaboration as the interaction of individuals

TABLE 1: Technology used for collaboration.

\begin{tabular}{ll}
\hline Author(s) name & List of technological tools \\
\hline Blau (2011) & Online discussion groups, integrated calendaring and collaborative authoring tools. \\
Gartner (2010) & Wikis, blogs, instant messaging, collaborative office and crowdsourcing. \\
Hudson (2011:3) & Group-decision support systems, audio-conferencing and Internet-based web conferencing. \\
$\begin{array}{l}\text { Vignarajah (2010) } \\
\text { Hill (2005) }\end{array}$ & E-mail, blog, micro-blogging, MySpace, Facebook, Twitter, Linkedln, Podcast, Wiki, YouTube, text-messaging, web conferencing, iPhone and iPad. \\
Crow (2002) & $\begin{array}{l}\text { E-mail exchange, drawing viewing sites (intranet and web-based), workflow and groupware software, teleconferencing and videoconferencing, } \\
\text { web-hosted meetings and computer-aided design (CAD). }\end{array}$ \\
\hline
\end{tabular}


engaged in a common task using electronic technology. Hudson (2011:3) presents a definition that encapsulates the objectives by denoting that collaboration occurs at any time where there are two or more people sharing complex information and knowledge building over the Internet.

Twinomurinzi (2007) explains that e-collaboration is the exchange of information, with the stakeholders playing a role in the outcome of the collaborative process. A more recent definition by Bettoni et al. (2011) described e-collaboration as a web-based group process of working, learning and sharing knowledge over distance in space and time.

Mindbuilt Technologies (2012) lists nine benefits of e-collaboration: increased efficiency, reduction in complexity, enhanced organisational intelligence, the development of stronger relationships, a reduction in travel costs, a reduction in long-distance phone calls, ease of installation and management, low overheads and a boost in employee morale.

The definitions and benefits listed above guided this article toward the proposed multi-dimensional matrix of e-collaboration factors.

\section{Knowledge development related to innovation}

E-collaboration is viewed as an improved mode of communication while using technology which varies from one interaction to another. Knowledge development and innovation can subsequently be listed as one of the outcomes of collaboration. The concepts contained in the preceding statement are discussed further in this section.

According to Rogers (2003), knowledge is the first step in the innovation-decision process. The other steps are persuasion, decision, implementation and confirmation. This endorses the relationship between knowledge and innovation. It also supports the idea that knowledge must precede innovation or be part thereof. Rogers (2003) further discusses the knowledge stage of the innovation-decision process which features three types of knowledge, namely awareness, how-to and principles. It is important to note that the 'how-to' knowledge can be associated with the selection of technology for use in an e-collaboration initiative.

Rogers (2003:12) describe innovation as an idea, practice or project that is perceived as new by an individual or other unit of adoption. This perception can be shared by one or many people and by one or many organisations or institutions. The definition of innovation is extensive and can also include products and processes for future implementation. From the above discussion, it follows that knowledge development and innovation can be linked to the improvement of e-collaboration. E-collaboration technology therefore assists in the development of knowledge and innovation. Because the focus is on ARIs, it is imperative to discuss their connection to collaboration.

\section{Academic and research institutions as a platform for collaboration}

The Academy of Science of South Africa (ASSAf) (2010) classified universities into three categories: university, comprehensive university and university of technology. Statutory research bodies and institutions that fund research are also included since they are involved in research and funding. A number of collaboration initiatives were noted between universities and other research institutions and amongst universities themselves:

1. A memorandum of understanding was signed between UNISA and Mogale City (UNISA web 2013).

2. Planning, Research and Management issues relating to Mogale City Parks Service/Business excellence which may include operational and scientific management of resources, internal and external customer needs/ satisfaction, management of biodiversity areas. (n.p.)

3. Mintek collaborates with the faculty of science at UJ (UJ web 2013): 'Collaboration between Mintek which is an organisation that works with the government on mineral technologies'. This collaboration connected a university, government and Mintek.

4. TUT web (2013) states that there is collaboration between the university and the French South African Institute of Technology (F'SATI), supported by the statement: '... a national asset that contributes to the creation of knowledge and prosperity as well as the transfer of technology in the Southern African region'. UCT web (2013) describes the following: '... is an important step towards building drug discovery and development capabilities in Africa - and educating the next generation of drug-discovery scientists in Africa'.

The above sections were intended to illustrate and motivate the focus on ARIs and their collaborative relationships. The foundational theories for this study are discussed as a lens for analysis and further investigation.

\section{Exploring theories related to e-collaboration}

Theory is a good foundation for discussions on knowledge development and innovation. Theories are important in academia since they present underpinning arguments and researched views for further development. The section to follow discusses DOI, MRT and GTM.

\section{Diffusion of innovation (DOI)}

With e-collaboration being a form of innovation, we are discussing DOI elements related to the work by Rogers (2003). Rogers (2003:4) emphasises that DOI is a social process that is simultaneously a technical matter. One needs to understand the social surroundings and context in order to achieve a successful diffusion of innovation. Rogers (2003:5) further asserts that, in order to launch a self-gathering diffusion process, one must work with the correct participants from the start. This highlights the impact of that perceptions concerning DOI can have and how it needs to be managed. In order to improve 
and understand knowledge development for the sake of innovation, one needs to identify and influence the correct participants with whom to start. Rogers (2003:5) regarded diffusion as both the planned and spontaneous spread of new ideas and later listed the four elements of DOI. Table 2 lists these elements together with practical translations related to this investigation.

\section{Media richness theory (MRT)}

Daft and Lengel (1984) argued that MRT originates from information processing, developed by organisational scientists. Communication between people is affected by the fitness of the media and the characteristics of the communication task. Daft and Lengel (1984) further specified that MRT advances the notion that the richness or leanness of communication is an objective property of the communication media. These authors conclude by defining MRT as the ability to facilitate shared understanding within a time interval.

Miles (2014) asserts that people who use a communication channel most fit for their task will be more effective than people who use a communication channel that does not fit. This supports the importance of selecting the best-suited channel of communication for a collaboration experience.

Regarding media richness, Daft, Lengel and Trevino (1987) provided four criteria:

1. Capacity for immediate feedback: The medium facilitates quick convergence on a common interpretation.

2. Capacity to transmit multiple cues: An array of cues, including physical presence, voice inflections, body gestures, words, numbers and graphic symbols, facilitate interpretation and meaning rather than simply the transfer of information or data.

3. Language variety: Numbers and formulas provide greater precision, but natural language conveys a broader set of concepts.

4. Capacity of the medium to have a personal focus: This refers to either the conveyance of emotions and feelings or the ability of the medium tailored to the specific needs and perspectives of the receiver.

The criteria above were useful for determining the levels of media richness and also contribute towards measuring e-collaboration. Kock (2012) investigated media-richness and noted that it presents a partial confirmation that group members perceive e-collaboration as a relatively unnatural medium.The findings show that there is a perceived increase in the quality of outcomes in a group if the quality of member contribution increases. There is a higher departmental heterogeneity enabled by the low disruptiveness inherent in the e-collaboration medium used that is applicable to an asynchronous communication medium. The above theoretical work by Kock (2012) supports the argument that media richness makes a significant contribution to the improvement of communication.

In support of MRT, Dennis and Valacich (1999:5) describe media synchronicity as the extent to which individuals work together on the same activity at the same time. Multiple dimensions are presented: media characteristics, task, functions and communication processes.

\section{Grounded theory method (GTM)}

According to an early definition by Glaser and Strauss (1967), GTM refers to the discovery of theory from data systematically obtained and analysed in social research. Trochim (2000) further suggests that the research starts with generative questions since it is a complex iterative process. Strauss and Corbin (1990) described GTM as an approach where the data collection, analysis and theory stand in a reciprocal relationship with each other.

\section{Research methodology and design}

GTM was the approach selected for this study as described in the section on theory. The authors noted that the findings in each stage influence subsequent stages. The methodology adopted is as follows:

1. Literature and theoretical reviews were conducted on the key topics and subjects.

2. The notes from the primary data collected in the main study were reviewed. The data were collected through observations and interviews with information-rich participants, guided by the ideas below:

- Purposive sampling was selected as suitable as described by Welman, Kruger and Mitchell (2010:63) as an approach which allows researchers to rely on their experience, ingenuity and/or previous research findings.

- Patton (1990) asserts that information-rich cases are those from which one can learn a great deal about issues of central importance to the purpose of the research. From this term, purposeful sampling is introduced.

- The observations were conducted by the researcher who was physically present at the selected ARIs.

TABLE 2: Diffusion of innovation elements and practical translations.

\begin{tabular}{lll}
\hline Element name & Description by Rogers (2003) & Practical translations related to this investigation \\
\hline Innovation & $\begin{array}{l}\text { 'An idea, practice or project that is perceived as new by an } \\
\text { individual or other unit of adoption'. }\end{array}$ & $\begin{array}{l}\text { Working together while making use of technology such as e-collaboration. } \\
\text { Communication channels }\end{array}$ \\
$\begin{array}{ll}\text { 'A process in which participants create and share informa- } \\
\text { tion with one another in order to reach a mutual under- } \\
\text { standing'. }\end{array}$ & $\begin{array}{l}\text { The different technological tools in place for collaboration to take place. } \\
\text { 'The impact and dimension of time on the diffusion'. }\end{array}$ & $\begin{array}{l}\text { Time needs must be considered closely when addressing the diffusion of knowledge } \\
\text { and innovation. }\end{array}$ \\
Social system & $\begin{array}{l}\text { 'A set of interrelated units engaged in joint problem solving } \\
\text { to accomplish a common goal'. }\end{array}$ & $\begin{array}{l}\text { These are the academic and research institutions involved in research. This social } \\
\text { system can also feature independent researchers. }\end{array}$ \\
\hline
\end{tabular}


3. A blog was developed, based on the preceding phases and on those elements identified as significant and requiring further investigation.

4. An analysis of findings from multiple sources was done, using open coding described by McCallin, Nathanial and Scott (2011) as an activity that can take place while data are being collected.

5. A multi-dimensional matrix for e-collaboration factors was developed.

6. Discussions on the matrix factors and other related phenomenon began.

The methodology also used a blog for data collection and for further exploring the ideas. Lavhengwa and Van der Walt (2011) motivated the use of websites by asserting their value in being a platform for e-collaboration. One of the fundamentals identified is that Lavhengwa and Van der Walt (2011) argue that websites must be dynamic or interactive to improve research. Nardi, Schiano, Gumbrecht and Swartz (2004) asserts that blogs are a promising tool for knowledge management. Hill (2005) further supports blogs as a tool that enables collaborative learning over the Internet. Blogs were therefore selected for their collaborative qualities and their ability to work towards knowledge management and innovation. A blog was developed. Data was collected over a period of two years, and multiple findings emerged in support of and a focus on knowledge development and innovation. Below is a list of selected posts as questions that were used on the blog:

1. Mobile platforms and collaboration: How easy are these to identify, and how dominant are they as contributors towards e-collaboration?

2. What are the tools and technology for e-collaboration?

3. What drives and influences e-collaboration?

Table 3 shows the categories of participants for the research.

The non-blog data were collected through observation, e-mail, telephone and personal interviews conducted by the researcher. Observations allowed the data collection to take place while other researchers and academics were participating in academic activities. The significant level of interest can be noted from Table 3 by focusing on the numbers and the quality of the contributions which will be detailed in the findings section.

\section{Findings and discussion}

This section addresses the findings, followed by a discussion of each of the findings.

TABLE 3: Categories of respondents.

\begin{tabular}{|c|c|c|}
\hline Category name & & Units \\
\hline $\begin{array}{l}\text { Non-blog participants: } \\
\text { (observation, emails, telephones and } \\
\text { interviews) }\end{array}$ & personal & 31 \\
\hline Blog participants - page views & & $837 \dagger$ \\
\hline Blog participants - published comments & & $73+$ \\
\hline
\end{tabular}

\section{Empirical findings}

The discussions that follow are related to the data collected from the participants as indicated in Table 3:

- Findings from non-blog participants: These were findings collected from 31 participants using multiple datacollection methods:

- Mutual interest was found to be a motivator for collaboration.

- Collaboration for learner support was listed as important for ARIs.

- Collaboration agreements were noted as essential between the participants.

- Geographical distances had previously limited and hindered opportunities for collaboration. This challenge has been addressed with the introduction of e-collaboration.

- Technology bridged the physical and logical gap between collaborators through the introduction of virtual environments.

- The knowledge economy is driven by electronic communication, thereby motivating an improvement in e-collaboration.

- The following collaboration technology was identified as prevalent: blogs, collaborative authoring tools, e-mail, telephone, fax and the Internet.

- Findings from the blog: These findings represent a list of the data collected from the e-collaboration blog:

- Auditors share knowledge at conferences, both physically and online.

- A number of auditors make use of templates from their companies for conducting audits. These can be in a word, excel or web-based solution with access control.

- Internal auditors collaborate through audit tools such as TeaMate. This tool enables them to work together towards a common outcome. Reports are later generated from the multiple contributions made by the audit team.

- Internal and external auditors collaborate at the start of an audit project. They later work together towards the end when they have to generate and distribute reports. This collaboration is done primarily through email. The review notes or comments or responses are shared amongst the auditors.

- Audit findings are shared since they are the main deliverables or output for auditors.

- Technology such as blogs is examples of e-collaboration.

- Discussions are quite helpful, and we need to invite more people involved in e-learning, e-collaboration and related research projects.

- Self-service kiosks are also used for e-collaboration.

- Social media and mobile devices make it easy to e-collaborate.

- E-collaboration facilitates the collaboration of researchers from disadvantaged parts of the world with affluent peers from well-resourced universities.

- Eagerness to use technology: This means that the introduction of new technology determines the possibility of advanced e-collaboration. 
What follows is a list of key discussion points from the findings. The Internet and blogs can be useful as a technology for knowledge development. The introduction of e-collaboration discussions motivated and improved knowledge-development opportunities. Innovation was the next achievement when collaborators started to discuss new ideas on how to solve their challenges. Creating platforms for working together improves knowledge development.

There were indications that geographical distances are no longer a limiting factor for collaboration when technology is introduced.

In the next section, the outcome of the multi-dimensional matric for e-collaboration factors is introduced with all the key elements.

\section{A multi-dimensional matrix for e-collaboration factors}

A matrix is denoted as a grid which presents arrangements containing elements that require focus. In describing media synchronicity, Dennis and Valacich (1999:5) present multiple dimensions which motivated the key elements of the matrix of e-collaboration factors. These are presented in Table 4 and discussed thereafter.

Generic driving factors: There are generic driving forces that must be addressed. The relevant ones for this investigation are people, economics, financial, political, leadership and training. These are factors that affect general initiatives. The other dimensions of the matrix for e-collaboration factors can also be featured in this section, but they are in separate sections with comprehensive details.

Environmental and virtual: This refers to the environment or setting where the e-collaboration takes place.

This collaboration can take many forms, from physical to logical and virtual work spaces. E-collaboration must not be geographically limited to a specific area.

According to Chetty and Mearns (2012), virtual environments present effective knowledge-management platforms through communities of practice. These virtual environments assist when the participants are in geographically dispersed areas.

Knowledge development and innovation: Knowledge development can be defined by the identified objectives and projects that are in focus at a particular time. Collaborators must identify knowledge areas of interest.
The relevant knowledge brokers must be identified and approached to participate and assist in the development of the initiative. Improvement in people's work and new ideas on how to gain advantage over their competitors can be featured in this section. Innovation will result as reviews and reflections are made concerning the knowledge that is being developed.

\section{Theoretical dimensions}

The sections below focus on each of the theoretical dimensions.

Diffusion of innovation: An understanding must be developed on how collaboration and the related technology are being adopted. Relevant updates must follow and ensure that this process is on-going. The collaborator must consider the four elements of DOI listed by Rogers (2003:5), being innovation, communication channels, time and the social system. The diffusion of e-collaboration must not be assumed but planned, monitored and updated as changes immerge over time.

Media richness: The richness of media presents both benefits and challenges. Rich e-collaboration media is good as it can lead to an improvement in the clarity of the interaction and messages. However, e-collaboration is considered a relatively unnatural medium of communication (Kock 2012). This problem needs to be addressed, and the related concerns must be understood by the participants. Media richness must be considered very carefully and will differ from case to case. Communication must be adjusted to meet the needs of the specific collaboration initiative.

Grounded theory method: There must be a reciprocal approach in developing an e-collaboration experience. The process must start with generative questions, as suggested by Trochim (2000), without any prescriptive outcomes.

\section{Tools and technology}

Tools and technology have an important role to play in all electronic interactions. The selection of these must be done with the involvement of all relevant participants.

Figure 1 represents a diagrammatic view of the multidimensional e-collaboration factors matrix.

The abovementioned multi-dimensional matrix of e-collaboration factors does not prescribe an application sequence. Each individual project must set an order that is relevant for it. The users can decide what is of importance to them and start with that dimension.

TABLE 4: Matrix of e-collaboration factors.

\begin{tabular}{ll}
\hline Dimensions & Key elements identifies \\
\hline Generic driving factors & Economics, finance, leadership, people, political and training. \\
Environmental and virtual & No geographical limitation and online access available anywhere. \\
Knowledge development and innovation & Identify knowledge areas of interest, identify relevant knowledge brokers and innovation must be initiated and improved. \\
Theoretical dimensions & Communication channels, time, social system, type and clarity of media in use for collaborating. An iterative process must be followed. \\
\hline Tools and technology & Email, blogs, teleconferencing, Internet, social-media networks and online discussion groups. \\
\hline
\end{tabular}




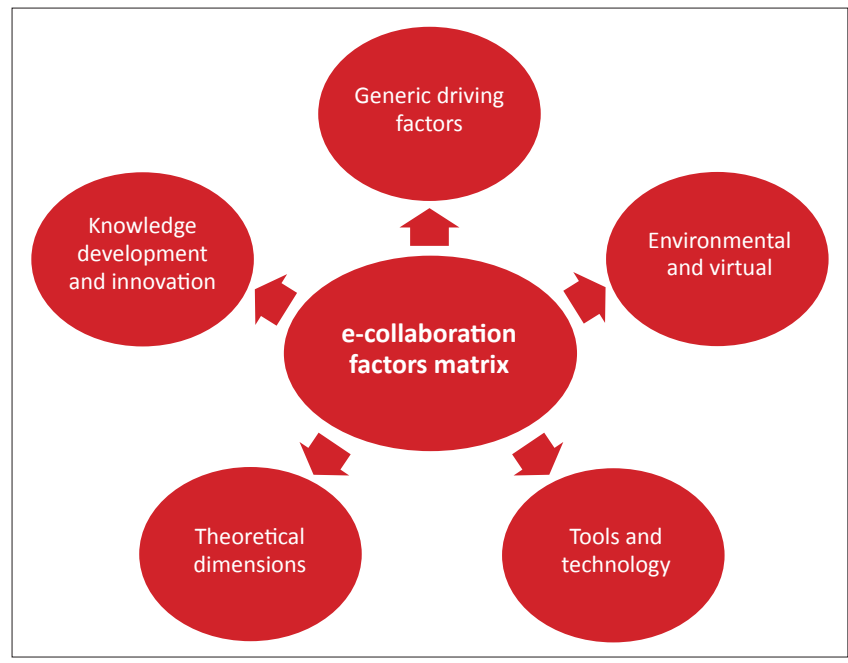

Source: Authors' own data.

FIGURE 1: Multi-dimensional matrix of e-collaboration factors.

\section{The use and value of an e-collaboration matrix}

This section initiates a discussion on the use of the matrix proposed. The primary purpose of the matrix is to assist in advancing a discussion on e-collaboration initiatives. The dimensions included are generic elements that would be adopted and addressed by collaborators. The matrix presents a high-level view of the focus of e-collaboration whilst focusing on research institutions. It is a guideline that can be applied, and it initiates a discussion for improved collaboration.

\section{Conclusion and prospects}

Work on e-collaboration was presented for knowledge development and innovation. The article concludes that there is more work that can be done towards understanding e-collaboration, knowledge development and innovation.

Whilst the article focuses on ARIs in order to identify the e-collaboration factors, other environments (business or government) can be investigated with varying results to update the e-collaboration matrix. The factors identified in the article are a starting point for further investigation. They are also generic enough as a useful guide to initiate other discussions and improvements. Further work can feature a number of ideas such as the following:

1. Consider other theories as a lens for further investigation

2. Knowledge brokering can be included as a dimension of the factors matrix with additional details also featured.

3. The matrix can be used in a team as a guide for improved knowledge development and innovation.

4. The intention of investigation is that collaboration teams must consider and address all the dimensions in the matrix.

5. The factors matrix can be extended by adding other dimensions specific to a geographical area or community for an improved level of specialised understanding.

The final conclusion is that collaboration should be reviewed and adapted as time progresses. The technology in use must also be revised with the changing needs whilst guided by the e-collaboration matrix.

\section{Acknowledgements Competing interests}

The authors declare that they have no financial or personal relationship(s) which may have inappropriately influenced them in writing this article.

\section{Authors' contributions}

T.J.L. (Tshwane University of Technology) initiated the paper; allocated and co-ordinated all the roles for all authors; maintained and consolidated all contributions into the manuscript from start to finish. J.S.W. (Tshwane University of Technology) advised and supervised on all aspects of quality. E.L. (Department of Minerals Resources) contributed in the start-up discussions, assisted in language and logical advice to enhance the flow of the manuscript. E.L. also contributed in examining and grouping the empirical findings. The author further assessed the matrix developed.

\section{References}

Academy of Science of South Africa (ASSAF), 2010, 'The PhD study: An evidencebased study on how to meet the demands for high-level skills in an emerging economy', Academy of Science of South Africa, Pretoria, viewed 09 October 2010, from http://www.assaf.org.za/wp-content/uploads/2010/10/40696Boldesign-PHD-small-optimised.pdf

Anyangwe, E., 2012, 'HE in FE: Top tips and resources to promote collaboration. Guardian Professional', viewed 29 February 2012, from http://www. guardian.co.uk/higher-education-network/blog/2012/feb/09/he-in-fecolleges?INTCMP=ILCNETTXT3487

Bechina, A.A. \& Ndlela, M.N., 2009, 'Success factors in implementing knowledge based systems', Electronic Journal of Knowledge Management 7(2), 211-218.

Bettoni, M., Bernhard, W., Eggs, C. \& Schiller, G., 2011, 'Participative faculty devel opment with an online course in e-collaboration', 6th International Conference on e-Learning, Kelowna.

Blau, I., 2011, 'E-collaboration within, between, and without institutions: Towards better functioning of online groups through networks', International Journal of e-Collaboration, 7(4), 37-60. http://dx.doi.org/10.4018/jec.2011100102

Caldwell, R.L., 2009, 'A new framework for anticipating the future', viewed 30 June 2013, from http://cals.arizona.edu/ caldwell/docs/decision-framework-1-25-09. pdf

Canadian Health Services Research Foundation (CHSRF), 2003a, 'Preliminary report: The practice of knowledge brokering in Canada's health system', viewed 15 July 2013, from http://www.cfhi-fcass.ca/migrated/pdf/event_reports/brokers final_e.pdf

Canadian Health Services Research Foundation (CHSRF), 2003b, 'CHSRF 2003 knowledge brokering workshop report', CHSRF knowledge brokering workshop, 02 October 2003, Montreal, viewed 15 July 2013, from http://www.chsrf.ca/ migrated/pdf/event_reports/Montreal_Report_e.pdf

Chetty, L. \& Mearns, M., 2012, 'Using communities of practice towards the next leve of knowledge management maturity', SA Journal of Information Management 14(1), Art. \#503, 9 pages. http://dx.doi.org/10.4102/sajim.v14i1.503

Crow, K., 2002, 'Collaboration: DRM associates', viewed 14 December 2012, from http://www.npd-solutions.com/collaboration.html

Daft, R.L. \& Lengel, R.H., 1984, 'Information richness: A new approach to managerial behaviour and organization design', Research in Organizational Behavior 6, 191233. http://dx.doi.org/10.2307/248682

Daft, R.L., Lengel, R.H. \& Trevino, L.K., 1987, 'Message equivocality, media selection, and manager performance: Implications for information systems', Management Information Systems Quarterly 11, 355-368.

De Jager, L., Buitendag, A.A.K. \& Van der Walt, J.S., 2012, 'Presenting a framework for knowledge management within a web-enabled living lab', SA Journal of Information Management 14(1), Art. \#506, 13 pages. http://dx.doi.org/10.4102/ sajim.v14i1.506

Dennis, A.R. \& Valacich, J.S., 1999, 'Rethinking media richness: Towards a theory of media synchronicity', Proceedings of the 32nd Hawaii International Conference on System Sciences, 5-9 January, Hawaii.

Gartner, 2010, 'Gartner identifies the top 10 strategic technologies for 2011', Analysts examine latest industry trends during gartner symposium, ITxpo, Orlando, 17-21 October, viewed 09 May 2014, from http://www.gartner.com/ it/page.jsp?id=1454221 
Glaser, B.G. \& Strauss, A.L., 1967, 'The discovery of grounded theory', Aldine Publications, New York.

Hill, C., 2005, 'Collaboration and e-learning', Interactive Technology in Education Conference 865, viewed 15 August 2014, from http://itec.sfsu.edu/wp/865wp/ s05_865_hill_collaboration.pdf

Hudson, A., 2011, 'The eight essential ingredients of small group e-collaboration technology', viewed 01 May 2013, from http://www.grouputer.com/papers/8 essential_ingredients.pdf

Kock, N., 2005, 'What is e-collaboration', International Journal of E-collaboration $1(1), 1-7$.

Kock, N., 2012, 'Unexpected outcomes of lean e-collaboration', viewed 25 February 2012, from www.cits.tamiu.edu/kockencycecollab/SampleManuscript2.doc

Lavhengwa, T.J. \& Van der Walt, J.S., 2011, 'Websites: A platform for researchers and academic institutions to e-collaborate', Paper read at the 10th Annual Information $\&$ South Africa.
Sout

McCallin, A., Nathanial, A. \& Scott, H., 2011, 'Grounded theory online supporting GT researchers: Getting started', viewed 29 September 2011, from http://www. groundedtheoryonline.com/getting-started.

Miles, J.A., 2014, 'Media richness theory: Management and organization theory', viewed 12 May 2014, from http://citeseerx.ist.psu.edu/viewdoc/download?do $=10.1 \cdot 1.108 .7118 \&$ rep $=$ rep $1 \&$ type $=p d f$

Mindbuilt Technologies, 2012, Why collaborate?, viewed 03 June 2012, from http:// www.mindbuilt.com/ecs/reasons.php Nardi, B., Schiano, D.J., Gumbrecht, M., Swartz, L. 2004, 'Why we blog',
Communications of the Association for Computing Machinery 47(12), 41-46. http://dx.doi.org/10.1145/1035134.1035163

Patton, M., 1990, Qualitative evaluation and research methods, Sage, Beverly Hills.

Rogers, E.M., 2003, Diffusion of innovations, 5th edn., Free Press, New York.

Sahin, I., 2006, 'Detailed review of Rogers' diffusion of innovations theory and educational technology: Related studies based on Rogers' theory, The Turkish Online Journal of Educational Technology 5(2), 14-23.

Soliman, R., Braun, R. \& Simoff, S., 2005, 'The essential ingredients of collaboration', Proceedings of the 2005 International Symposium on Collaborative technologies
and Systems, p. 366, Saint Louis. http://dx.doi.org/10.1109/ISCST.2005.1553336
Steyn, P. \& Du Toit, A., 2009, 'Maximising the value of knowledge workers', South African Journal of Information Management 11(1).

Strauss, A. \& Corbin, J., 1990, Basics of qualitative research: Grounded theory procedures and techniques, Sage, London.

Thomas, R.J., 2013, 'The three essential ingredients of great collaborations', Harvard Business Review, viewed 12 May 2013, from http://blogs.hbr.org/cs/2011/06/ the three_essential_ingredient.html

Trochim, W., 2000, 'The research methods knowledge base', 2nd edn., Atomic Dog Publishing, Cincinnati.

Tshwane University of Technology (TUT web), 2013, 'TUT signs new agreement with French technology partner', viewed 30 June 2013, from http://www.tut.ac.za/ News/Pages/TUTsignsnewagreementwithFrenchtechnologypartner.aspx

Twinomurinzi, H., 2007, 'E-collaboration for development innovations in rural communities: A South African experience', Proceedings of the 9th International Conference on Social Implications of Computers in Developing Countries, São Paulo, Brazil, 28-30 May.

University Of Cape Town (UCT web), 2013, 'Collaboration with pharmaceutical giant to foster drug development in Africa', UCT Monday Paper, 32(3), viewed 30 June 2013, from http://www.uct.ac.za/downloads/news.uct.ac.za/monpaper/ mp32_03.pdf

University of Johannesburg (UJ web), 2013, 'Mintek - faculty of science collaboration', viewed 30 June 2013, from http://www.uj.ac.za/en/research/ research information/strategic partnerships/national partnerships/pages/ mintek-facultyofsciencecollaboration.aspx

University of South Africa (UNISA web), 2013, 'Collaborations', viewed 30 June 2013, from http://www.unisa.ac.za/Default.asp?Cmd=ViewContent\&Content ID $=19426$

Vignarajah, A., 2010, 'Current trends in computer technology', Proceedings of the Global Business and Technology Association (GBATA), Twelfth Annual International Conference, pp. 911-915, Kruger National Park Vicinity, South Africa, 5-9 July.

Welman, J.C., Kruger, S.J. \& Mitchell, B., 2010, Research methodology, 3rd edn., Oxford University Press, Cape Town. 